\title{
Written Asthma Action Plans (WAAPs) in Melbourne general practices: a sequential mixed methods study
}

\author{
*Nabil Sulaimana, Rosalie Aroni ${ }^{b}$, Francis Thien, Rosa Schattner ${ }^{b}$, Pamela Simpson $^{\text {, }}$ \\ Eleonora Del Colle ${ }^{d}$, Rory Wolfe $^{b}$, Michael Abramson $^{b}$
}

\author{
a Department of Family and Community Medicine, University of Sharjah, Sharjah University City, United Arab Emirates \\ ${ }^{b}$ School of Public Health \& Preventive Medicine, Monash University, Melbourne, Australia \\ ' Department of Respiratory Medicine, Eastern Health, Box Hill Hospital, Victoria, Australia \\ d Pulmetrics Pty Ltd, East Doncaster, Victoria, Australia
}

Received 7th June 2010; revised 21st October 2010; accepted 12th November 2010; online 18th February 2011

\begin{abstract}
Aim: To investigate ownership and perceived utility of written asthma action plans (WAAPs) in general practice.

Methods: Questionnaires were completed by 225 adults and 75 children with GP-diagnosed asthma from 31 practices. Regression models for WAAP ownership allowed for confounders and clustering by practice. Five audio-recorded focus groups were conducted before questionnaire implementation and, 12 months later, six focus groups and additional in-depth interviews with 29 patients and 16 doctors were conducted. Transcripts were submitted to content and thematic analyses.

Results: A total of $37 \%$ of adults and $47 \%$ of children had WAAPs. Adults reporting spontaneous shortness of breath, an emergency presentation in the previous 12 months, or frequent GP visits were more likely to have a WAAP. Qualitative data indicated that few acknowledged receipt or use of one. Those who remembered receiving a WAAP found it useful in asthma management in conjunction with verbal advice given by their GP. WAAPs were perceived by some patients as an indicator of doctor competence which, in turn, was viewed as signifying better management of asthma by the patient even if the WAAP was never actually used.

Conclusions: Ownership of WAAPs is still low. Additional and more effective strategies are required to improve rates of GP prescription of WAAPs.

(C) 2011 Primary Care Respiratory Society UK. All rights reserved.

N Sulaiman et al. Prim Care Respir J 2011; 20(2): 161-169

doi: $10.4104 /$ pcrj.2011.00010
\end{abstract}

Keywords asthma, action plan, primary care

See linked editorial by Reddel on pg 116

The full version of this paper, with online Appendix,

is available at www.thepcrj.org

\section{Introduction}

Asthma is a chronic disease with exacerbations of symptoms which are associated with school/work absenteeism, emergency department (ED) visits, hospitalisations, and death. ${ }^{1-3}$ Written asthma action plans (WAAPs) assist asthma patients in decreasing the severity and duration of exacerbations. ${ }^{4} \mathrm{~A}$ plan is a written set of instructions given to patients or parents for daily treatment, initiation or modifying treatment for acute exacerbation, and advice on when to seek medical consultation.

The most recent systematic review ${ }^{4}$ of five trials in children showed that WAAP use significantly reduced acute care visits, school absenteeism and nocturnal wakening, and improved symptom scores. Compared with peak flow-based plans, symptom-based plans significantly reduced the risk of a patient requiring an acute care visit. Thus, symptom-based plans are superior to peak flow-based plans in children and adolescents. ${ }^{4}$ However, in adults there is no difference between the two types. ${ }^{5}$

The National Asthma Council (NAC) of Australia, ${ }^{2}$ the American National Asthma Education and Prevention Program ${ }^{6}$ as well as the Global Initiative for Asthma ${ }^{7}$ and many other

\footnotetext{
* Corresponding author: Dr. Nabil D Sulaiman, Department of Family and Community Medicine, University of Sharjah, Building M27-119, Sharjah University City, Sharjah, 27272, United Arab Emirates. Tel: +97165057206 E-mail: nsulaiman@sharjah.ac.ae
} 
asthma guidelines therefore recommend that all patients with asthma be prescribed a WAAP, ${ }^{8-10}$ especially those with a history of frequent and severe asthma exacerbations. ${ }^{1}$ However, several studies have reported that only $25-56 \%$ of eligible patients receive a WAAP. ${ }^{2,89}$ A WAAP is only one part of an education package comprising self-management, scheduled visits in how to use medications, and how to monitor symptoms and lung function. ${ }^{10}$ The WAAP is therefore optimal when supervised by a physician and accompanied by a comprehensive selfmanagement programme, leading to reductions in exacerbations in both children and adults. ${ }^{11-14}$

This analysis is part of SPIRO-GP, a cluster randomised controlled trial (RCT) of the effectiveness of spirometry in Australian general practices. We adopted a mixed methods approach to investigate WAAPs among trial participants using data from baseline questionnaires, focus groups, and interviews conducted before and after the trial.

\section{Methods}

This study uses a sequential mixed methods design. ${ }^{15}$ It began with a qualitative phase incorporating the use of two focus groups with GPs and practice nurses in each group $(n=13)$ and an additional three focus groups of 4-8 patients each with asthma or chronic obstructive pulmonary disease (COPD, $\mathrm{n}=26$ ). The second phase was a cross-sectional analysis of baseline data from a cluster RCT of 31 general practices in Melbourne, Australia. The final phase included content and thematic analyses of qualitative data drawn from six focus groups of 4-6 patients each $(n=28)$, and individual in-depth interviews with 29 patients and 16 doctors conducted after implementation of the trial. This design was used to enhance the development and implementation of tools in the cluster RCT phase and to enable a more detailed examination of outcomes including why participants chose to use or not to use WAAPs. The study was approved by the Standing Committee on Ethics in Research Involving Humans at Monash University and The University of Melbourne ethics committees.

The RCT methods have been reported in detail elsewhere. ${ }^{16}$ Briefly, 48 general practices (Figure 1) were recruited through Divisions of General Practice in metropolitan Melbourne and surrounding areas and 31 of these practices completed the protocol for the recruitment of patients. Non-participating practices were unable to search their databases, citing among other reasons lack of time, lack of staff, or change of mind by the principal GP. The participating practices recruited patients aged 8-70 years with doctor-diagnosed asthma who understood English and provided written consent to participate. Children with infrequent episodic childhood asthma and those with other complex medical conditions such as mental illness or cancer were excluded. This analysis included 49 children (age 8-13 years), 26 young people (age 14-17 years) and 225 adult patients with asthma (age 18-70 years).

The questionnaire was self-administered by adults or parents of children, and practice medical records were reviewed to extract other relevant data. The adult questionnaire was based on the European Community Respiratory Health Survey (www.ecrhs.org). The parental questionnaire was based on the Improving Child and Adolescent Asthma Management. ${ }^{17}$ The specific questions on WAAPs are given in Appendix 1. Asthma control was assessed with a validated five-item test. ${ }^{18}$ Socioeconomic status was estimated from the Socio Economic Index For Areas (SEIFA) of advantage/disadvantage for the postcode of residence (Australian Bureau of Statistics 2006, www.abs.gov.au/ausstats/abs@.nsf/mf/2039.0).

\section{Qualitative methods}

Prior to administration of the baseline questionnaire, five focus group sessions were conducted - two with healthcare providers and three with patients with asthma or COPD - to elicit perceptions and experiences of key issues regarding the use of spirometry in general practice in Melbourne. Purposive maximum variation sampling ${ }^{15}$ was used for the baseline focus group sessions with clinicians and practice nurses. There was an attempt to recruit health professionals who were members of solo and group practices as well as those with or without practice nurses and from geographically distinct locations. Patients were recruited from practices across the Victorian Divisions of General Practice. Sampling via these groupings was viewed as enabling access to socioeconomically, culturally, and linguistically diverse participants. Two facilitators (RA and RS) conducted the focus group sessions which were audio- recorded and transcribed verbatim. One issue that was raised with patient participants was whether WAAPs were provided and, if so, whether they were they useful (see Appendix 1, available online at www.thepcrj.org). Healthcare professionals were asked if they provided patients with WAAPs, whether they were viewed as useful in asthma self-management, and whether they might be more effective if combined with spirometry.

Six focus groups with patients drawn from the various arms of the study were conducted after completion of the RCT. Practitioners who were recruited into the RCT were invited to participate in subsequent focus groups, but this was found to be too difficult in terms of time so doctors were invited to participate in a 20 min telephone interview. Indepth semi-structured audio-recorded telephone interviews ${ }^{19}$ were conducted with 16 clinicians from each arm of the RCT and with 29 patients who had participated in the study but were unable to attend focus group sessions. The audiorecorded data were transcribed verbatim in preparation for analysis. Both content and thematic analysis ${ }^{20}$ were used to examine these qualitative data sets; that is, transcripts were 
Figure 1. SPIRO-GP Study: Ownership of written asthma action plans (WAAPs) Quantitative analysis limited to patients with doctor-diagnosed asthma aged 8-70 years $(n=300)$. Focus groups were held before the trial, focus groups and interviews after the trial.

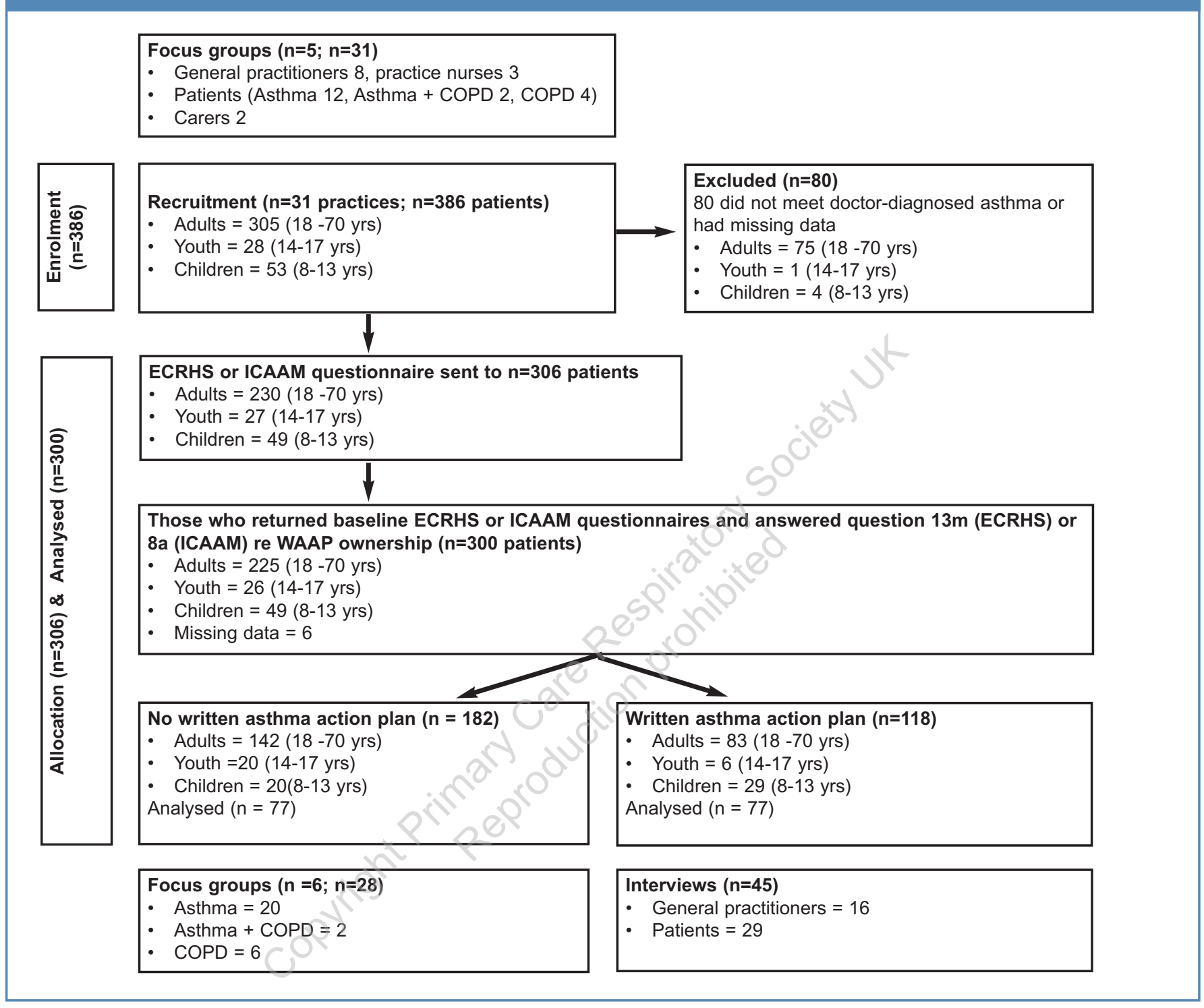

read and re-read to enable development of a coding frame, the data were coded for examination of content, and then themes were examined across the whole data set as well as in the context of each focus group discussion and each individual interview.

Symbolic interactionism ${ }^{21}$ was the conceptual framework that informed the interpretation of the qualitative data sets. According to this framework, people attach meanings to symbols and they then act according to their subjective interpretations of these symbols in their social interactions. Indepth interviews and focus group sessions were conducted in order to obtain the best understanding of the subjective interpretations that participants attached to the use of spirometry and also the relevance and use or non-use of WAAPs.

\section{Statistical analysis}

Logistic regression analysis was used to determine both univariate and multivariate odds ratios and $95 \%$ confidence intervals. Robust standard errors were calculated to allow for within-cluster correlation at the practice level. All analyses were performed using Stata Version 11 (StataCorp LP, College Station, Texas, USA, 2009).

\section{Results}

\section{Patient characteristics}

A total of 225 adult patients completed the baseline questionnaire. Of these, 83 (37\%) reported having a WAAP and 142 did not have a WAAP. Patient characteristics including gender, age, and current smoking are shown in 
$\mathrm{N}$ Sulaiman et al.

\begin{tabular}{|c|c|c|c|c|}
\hline & $\begin{array}{l}\text { No written } \\
\text { action plan } \\
\qquad(n=142)\end{array}$ & $\begin{array}{r}\text { Written } \\
\text { action plan } \\
(n=83)\end{array}$ & $\begin{array}{l}\text { Odds ratiot } \\
\qquad(95 \% \mathrm{Cl})\end{array}$ & $\mathrm{p}$ value \\
\hline Age, median (IQR) & $55(47-63)$ & $60(52-65)$ & $1.01 *(0.99$ to 1.03$)$ & 0.36 \\
\hline Gender (male), N (\%) & $40(32)$ & $20(27)$ & $0.7(0.4$ to 1.5$)$ & 0.39 \\
\hline Socioeconomic status, mean (SD) & $1032(61)$ & $1031(61)$ & $1.00 *(0.99$ to 1.01$)$ & 0.90 \\
\hline Asthma score, median (IQR) & $20(16-23)$ & $18(13-21)$ & $0.92 *(0.87$ to 0.98$)$ & 0.01 \\
\hline Asthma score 'on target', N (\%) & $80(56)$ & $34(41)$ & $0.5(0.3$ to 0.9$)$ & 0.02 \\
\hline \multicolumn{5}{|l|}{ Study arm: } \\
\hline Group A, N (\%) & $48(34)$ & $25(30)$ & $0.7(0.4$ to 1.5$)$ & 0.36 \\
\hline Group B, N (\%) & $61(43)$ & $34(41)$ & $0.7(0.5$ to 1.3$)$ & 0.32 \\
\hline Group C, N (\%) & $33(23)$ & $24(29)$ & 1 & \\
\hline Wheezing in the previous 12 months, $\mathrm{N}(\%)$ & $122(87)$ & $73(89)$ & $1.2(0.4$ to 3.6$)$ & 0.69 \\
\hline Chest tightness in the previous 12 months, $\mathrm{N}(\%)$ & $67(50)$ & $51(63)$ & $1.7(0.9$ to 3.1$)$ & 0.09 \\
\hline Spontaneous shortness of breath, N (\%) & $48(34)$ & $45(55)$ & $2.4(1.5$ to 3.6$)$ & $<0.001$ \\
\hline Nocturnal cough in the previous 12 months, $\mathrm{N}(\%)$ & $88(62)$ & $55(66)$ & $1.2(0.7$ to 2.1$)$ & 0.55 \\
\hline Sputum in the previous 12 months, $\mathrm{N}(\%)$ & $95(75)$ & $61(82)$ & $1.5(0.7$ to 3.2$)$ & 0.27 \\
\hline Attack of asthma in the previous 12 months, $\mathrm{N}(\%)$ & $74(57)$ & $51(65)$ & $1.4(0.8$ to 2.4$)$ & 0.21 \\
\hline Emergency presentation in the previous 12 months, $\mathrm{N}(\%)$ & $8(7)$ & $10(16)$ & $2.4(1.1$ to 5.2$)$ & 0.03 \\
\hline Hospital admission in the previous 12 months, $\mathrm{N}(\%)$ & $4(5)$ & $6(10)$ & $2.0(0.5$ to 7.6$)$ & 0.29 \\
\hline \multicolumn{5}{|l|}{ Smoking category: } \\
\hline Never smoker, N (\%) & $68(50)$ & $40(50)$ & 1 & \\
\hline Former smoker, N (\%) & $48(35)$ & $28(35)$ & $1.0(0.5$ to 1.9$)$ & 0.98 \\
\hline Current smoker, N (\%) & $21(15)$ & $12(15)$ & $1.0(0.4$ to 2.3$)$ & 0.95 \\
\hline \multicolumn{5}{|l|}{ Adherence to medication, N (\%) } \\
\hline 0 (perfect adherence) & $42(32)$ & $22(28)$ & 1 & \\
\hline 1 & $23(17)$ & $17(22)$ & $1.4(0.6$ to 3.2$)$ & 0.42 \\
\hline 2 & $21(16)$ & $16(20)$ & 1.5 (0.8 to 2.8$)$ & 0.25 \\
\hline 3 & $17(13)$ & $17(22)$ & 1.9 (1.0 to 3.6$)$ & 0.05 \\
\hline 4 (complete non-adherence) & $29(22)$ & $6(8)$ & $0.4(0.1$ to 1.2$)$ & 0.09 \\
\hline GP visit in the previous 12 months, $\mathrm{N}(\%)$ & $74(59)$ & $60(78)$ & $2.5(1.4$ to 4.4$)$ & 0.002 \\
\hline Regular appointments with GP, N (\%) & $11(28)$ & $20(54)$ & $3.0(1.0$ to 8.8$)$ & 0.05 \\
\hline
\end{tabular}

Table 1. Those with WAAPs were slightly - albeit not significantly - older and more likely to be female, but socioeconomic status was virtually identical. Half the patients had never smoked, over one-third were former smokers, and only $15 \%$ were current smokers; this did not differ between groups.

Baseline questionnaires were also completed by the parents of 49 children and by 26 young people. Demographic and clinical characteristics are summarised in Table 2. On average, those with WAAPs were about two years younger and slightly more likely to be male than those without WAAPs. There were no significant differences in nocturnal symptoms or limitation of sport during the preceding three months. Only four reported a hospital admission in the preceding 12 months.

Adults with better asthma control were half as likely to have a WAAP (Table 1). Patients with spontaneous shortness of breath and those who had an emergency presentation in the previous 12 months were more likely to have a WAAP. Adults with poorer adherence to medications were less likely to have WAAPs. On average, children with WAAPs were younger and adults were older than those without WAAPs. Children and young people who had an emergency presentation in the previous 12 months were almost 19 times more likely to have a WAAP. Those who had visited a GP for an asthma attack in the previous 12 months were three times more likely to have a WAAP.

The multivariate logistic model (Figure 2) showed that spontaneous shortness of breath was the only independent predictor of a WAAP after allowing for potential confounding by age, gender, socioeconomic status, asthma control, ED presentations, and clustering by practice. Patients reporting spontaneous shortness of breath in the preceding 12 months 


\begin{tabular}{|c|c|c|c|c|}
\hline & $\begin{array}{l}\text { No written } \\
\text { action plan } \\
\qquad(n=40)\end{array}$ & $\begin{array}{r}\text { Written } \\
\text { action plan } \\
(n=35)\end{array}$ & $\begin{array}{l}\text { Odds ratio } \\
(95 \% \mathrm{Cl})\end{array}$ & $p$ value \\
\hline Age, mean (SD) & $13.8(2.7)$ & $11.7(2.5)$ & & 0.003 \\
\hline Gender (male), N (\%) & $18(45.0)$ & $23(65.7)$ & & 0.10 \\
\hline \multicolumn{5}{|l|}{ Study arm: } \\
\hline Group A, N (\%) & $15(37.5)$ & $17(48.6)$ & & 0.10 \\
\hline Group B, N (\%) & $17(42.5)$ & $7(20.0)$ & & \\
\hline Group C, N (\%) & $8(20.0)$ & $11(31.4)$ & & \\
\hline Nocturnal symptoms in the previous 3 months, $\mathrm{N}(\%)$ & $15(37.5)$ & $15(42.9)$ & & 0.65 \\
\hline Limited sport in the previous 3 months, $\mathrm{N}(\%)$ & $12(30.0)$ & $10(29.4)$ & & 1.0 \\
\hline Emergency presentation in the previous 12 months, N (\%) & $1(3.1)$ & $9(37.5)$ & $18.6(1.9$ to 179$)$ & 0.01 \\
\hline Hospital admission in the previous 12 months, $\mathrm{N}(\%)$ & $1(3.1)$ & $3(13.6)$ & & 0.29 \\
\hline Peak flow use in last 3 months: & & & & 0.38 \\
\hline At home & $5(12.5)$ & $3(8.6)$ & & \\
\hline At GP & $2(5.0)$ & $5(14.3)$ & & \\
\hline No & $32(80.0)$ & $27(77.1)$ & & \\
\hline Don't know & $1(2.5)$ & $0(0)$ & & \\
\hline Visited GP for asthma attack in last 12 months, N (\%) & $19(52.8)$ & $26(78.8)$ & $3.3(1.3$ to 8.7$)$ & 0.01 \\
\hline
\end{tabular}

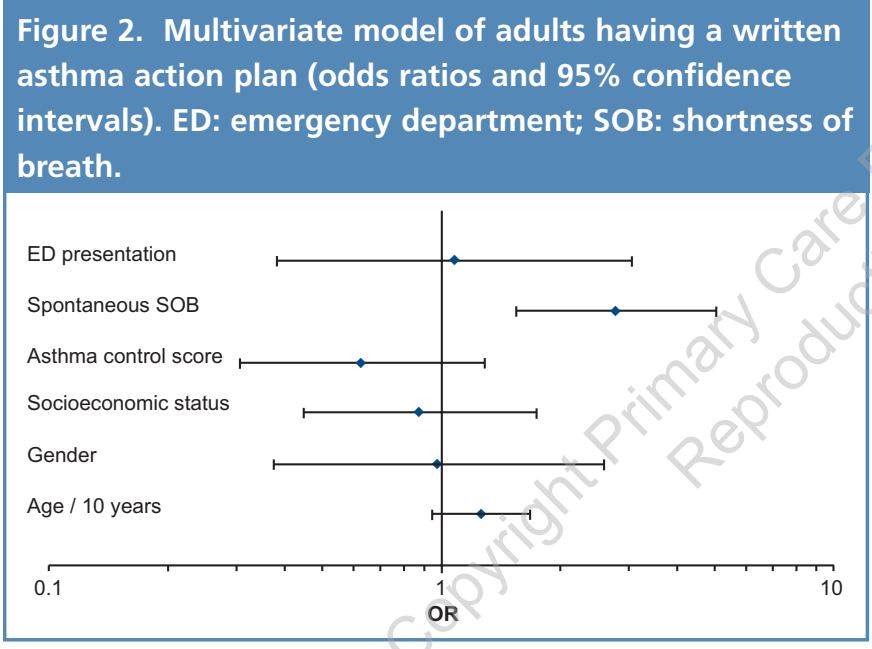

were almost three times more likely to have a WAAP than those who did not report this symptom.

\section{Qualitative analysis}

Qualitative data were analysed for the key themes and also for their conceptual relationship, or otherwise, to the key findings drawn from the quantitative data as part of the process of simultaneous triangulation. ${ }^{20}$ The quotations provided in Boxes 1-7 were selected as representative of key patterns evident in the qualitative data sets and were drawn only from participants with asthma. Content and thematic analyses of the patient focus group discussions conducted both before and after the implementation of the baseline questionnaire indicated that few patients remembered receiving a WAAP (Box 1).

Where ownership of a WAAP was mentioned, it was

\section{Box 1}

Interviewer: "Did any of you receive a written asthma action plan?" Participant A (over 45, male, asthma): "What's that?"

Interviewer: "It's either a set of instructions that your doctor wrote down while discussing with you what you need to do at home with your asthma or a special card or sheets with ..."

Participant A: "Nup, nothing written down ... I don't think I've heard of that before."

Participant B (retired, female, asthma): "I'm not sure, I can't remember getting anything like that. What about you?"

Participant C (retired, female, asthma): "Um ... um, maybe .. um ... no, I don't think so." (Pre-trial Patient Focus Group 1)

Interviewer: "So did your doctor give you some instructions on what to do if you had an asthma attack? Did she write them down?" Participant F (retired, female, asthma): "Well, ah ... um, well we talked about what to do and she was really helpful about that but ... um."

Interviewer: "But was it something you just had to remember or did she actually give you a piece of paper or a card with instructions about what to ....?"

Participant F: "No, I don't think so, but that was all a long time ago, you know. I've been living with this problem for a long time and we both know what I have to do (laughs). It's not hard to figure out really. Mind you, it'd probably be good to have something like that. Everything helps." (Pre-trial Patient Focus Group 2)

perceived as an indicator of the competence of the doctor and this in turn was viewed as signifying better management of asthma by the patient even if the WAAP was never actually used (Box 2).

Both content and thematic analyses of the data drawn 


\section{Box 2}

Interviewer: "Okay. Do any of you have a written asthma action plan or know what a written asthma action plan is?"

Participant M (retired, female, asthma): "Yes, yes, me!"

Interviewer: "Can you tell me a little about yours?"

Participant M: "It's on my fridge door. My doctor's very good. He gives me everything I need. He knows what he's doing and then I am the best patient because I am prepared for everything!"

Participant N (over 45, female, asthma): "Mine didn't give me one but he explains it all. It doesn't matter he didn't write it. It's good enough."

Participant O (over 45, female, asthma): "Yes, but mine is really good you know because she gave me one right at the start and that's because she's great, a really excellent doctor, and then everyone knows what to do."

Interviewer: "Everyone? Do you ...?"

Participant O: "It's not just me, it's my family too. Then everyone in the house knows that if I get really bad they need to follow the plan, you know, in case I have to go to hospital."

Interviewer: "And you discussed that with your doctor, so the doctor has a copy and you have a copy?"

Participant O: "She handed it to me."

Participant M: "I've got a printed out programme that he devised, my wonderful man devised, and if it got worse, we do this and then this and then if nothing works I go to hospital." (Pre-trial Patient Focus Group 1)

from the consumer focus groups and telephone interviews conducted after the 12-month period concurred with the quantitative findings that those patients who experienced acute episodes of asthma were more likely to have been provided with a WAAP. Some of these participants also indicated that, while they had been given a WAAP in childhood, they did not have to refer to it because it was 'second nature now' (Box 3).

\section{Box 3}

Interviewer: "... do you have an emergency plan or a written asthma action plan, have you been given that by your doctor?"

Participant P (48, female, asthma): "I have been given it but ... um."

Interviewer: "Where does it sit? On your fridge?"

Participant P: "No."

Interviewer: "Somewhere in your drawer?"

Participant P: "No."

Interviewer: "Do you think it is useful to have?"

Participant P: "I think a lot of us are old enough and have had enough experience. We know we know it." (Post-trial Focus Group)

Alternatively, several participants knew what was in it but did not actually use it when faced with an acute episode. Thematic analysis indicated that having a WAAP - even if not actually used for an event - provided a sense of security.

Participant P: "It's really good to have there but I didn't really need to use it. I felt safer knowing that I had it there to refer to."

Thematic analysis of the transcripts of the focus group prior to completion of the study and the telephone interviews with GPs after completion of the study indicated that there were mixed perceptions of the utility and effectiveness of WAAPs. Three key themes regarding perceptions of practice were evident. The first and most commonly stated perception of their own practice by GPs was that provision of WAAPs was simply standard practice (Box 4).

\section{Box 4}

Interviewer: " ... do you write asthma and COPD plans?"

Participant: "Yes ..."

Interviewer: "Do you think that increased over the time of the study or it stayed about the same?"

Participant: "It probably stayed the same, yes. Yes I always write it." (6)

Within this mode of practice, there were those who suggested that WAAPs were good in principle but needed to be part of a broader strategy to prevent exacerbations or they were not useful (Box 5).

\section{Box 5}

Interviewer: "What about written asthma action plans? Have you written any in the last 12 months?"

Participant: "Yeah, I do. Once again it's a time limiting thing, there is a small payment for it, but often it's not really what it's all about. It really depends on whether the patients have a peak flow meter, really understand the piece of paper and go through it or ... you know, I do it occasionally. I think that having access to the doctor and also learning something from every contact is important. So teaching the patient about their asthma at opportune times I think is really important, so that they start to learn more about the treatment and then self-initiating treatment. You can call that a plan, whether it's a written one, but educating the patient to understand it, that's the critical bit from my point of view."

Interviewer: "Yes."

Participant: "They have a piece of paper and then walk in, you know puffing and wheezing and not having initiated anything is of no value to anyone."

Another element within this perceived mode of practice was the focus on who would most gain from receiving WAAPs. The GP participants suggested that WAAPs were most useful in the care of children with asthma rather than adults with asthma (Box 6).

The final perception of practice expressed by GPs was the writing of fewer WAAPs over time (Box 7). 


\section{Box 6}

Participant: "Yes, in the last 12 months I definitely have done some."

Interviewer: "Do you find them useful? Do your patients find them useful?

Participant: "... The people I think who want them most are the mothers of kids with asthma ... They do find them useful to refer to, but they also find them useful ... give to someone like the school or if the child is sleeping over ... most adults seem to get by without one, so probably everyone should have one. Anyone that's on chronic medication and has been in hospital and things like that, but with kids is the main place that I would use it."

\section{Box 7}

Interviewer: "What about written asthma action plans? Would you have written any over the last 12 months?"

Participant: "Very few, in fact, I've written less and less as time has gone by. The feeling I'm getting is that asthma has been much better treated over the last couple of years. I think some of the newer puffers around have made asthma much less of an issue than it used to be and so a lot of my lung disease is in older people."

This was a minority view. Only two other participants expressed similar views.

These perceptions of practice illuminated the key theme of legitimation of clinical decision-making which became evident in simultaneous triangulation of the data sets.

\section{Discussion}

This is a report on a mixed methods study which included an examination of the use of WAAPs in Melbourne general practices. Evidence-based guidelines recommend the use of WAAPs for all patients with asthma - especially those with moderate to severe asthma - to improve health outcomes and reduce utilisation of health services. Ownership of WAAPs among children in this study was higher than in our previous study of children with asthma aged 2-14 years attending GP clinics in the northern suburbs of Melbourne in 2001.22 Despite an improvement in rate of ownership, it was still below the recommended guidelines and requires some explanation. The improvement between 2001 and 2008 might be due to various intervention programmes directed at GPs and the general population, including the Asthma 3+ plan, ${ }^{23}$ practice incentive payments, chronic disease management initiatives, asthma clinics in general practice as well as the Victoria Hospital Admissions Risk Program. The comments about funding made by GPs in the early focus groups and the subsequent telephone interviews highlight this particular explanation for the increase in the provision of WAAPs over that period to become a regular practice for some GPs. Another explanation may be the geographical/socioeconomic differences between the two studies as the earlier study was conducted in disadvantaged areas of north-western Melbourne while the current study recruited patients mainly from the more affluent eastern and southern suburbs.

Adults and children with asthma requiring presentation to an ED or frequent GP visits during the 12 months prior to study entry were much more likely to have a WAAP than those not requiring ED or GP care. Similarly, children with poorer asthma control scores were more likely to have a WAAP, indicating that patients with poorly controlled asthma are more likely to use health services and more likely to have a WAAP prescribed by GPs or hospital doctors. In line with these results, adults and children with frequent GP visits or an ED presentation were 2-3 times more likely to have a WAAP. These findings concur with the results of our previous study ${ }^{22}$ that children who reported an attack during the three months prior to interviews or reported GP or ED presentations or more severe asthma were more likely to have a WAAP. In the South Australian Population Survey, patients over the age of 15 years who suffered from weekly asthma symptoms were more likely to have a peak flow meter and a WAAP. ${ }^{24}$ Again these findings are not unexpected - the more severe asthma and the poorer control, the more utilisation of health services, hence more likely to have a WAAP.

These findings were supported by the qualitative data from interviews and focus groups at baseline and 12 months. Those who were using a WAAP were doing so in conjunction with GP advice.

This was consistent with the most recent systematic review that symptom-based WAAPs are superior to peak flow-based plans in children and adults. ${ }^{4}$ Two Melbourne studies ${ }^{25,26}$ have shown that verbal advice rather than written asthma instructions were more likely to be given by GPs. Our analysis of the qualitative data confirmed this view. It provided further explanation of how clinicians perceived and legitimated their own clinical practices by reference to the perceived utility and efficacy of WAAPs.

Also, this was consistent with our results that patients with poor asthma control who had more frequent ED presentations were more likely to have WAAPs. This suggests that either hospital ED doctors are more likely to provide written instructions than GPs, or maybe that efficient GPs are singling out ED attenders for asthma reviews and subsequently providing WAAPs.

More children than adults have a WAAP and younger children were more likely to receive a WAAP. This might be explained on the basis of the greater need for modification of medications in children than in adults. ${ }^{21}$ Our qualitative data suggested an additional complementary explanation, that perhaps kindergarten and school staff are perceived as requiring students to bring a WAAP and hence parents engage 
more directly with doctors about receiving a WAAP for their children's school attendance. In addition, GPs perceived family members as feeling more secure and at ease when children with asthma require supervision outside the home (at social events like sleepovers) and the parents can provide medically approved guidance for management of potential acute exacerbations.

Ownership of a WAAP does not necessarily indicate that it is used. Our qualitative data provided some understanding of patients' rationale for non-use - for example, with the patient perception of self as expert. This concurs with our previous findings. ${ }^{22}$ In addition, our qualitative data indicate that some GPs who provide WAAPs may not have based them on a more extensive review process whereas others were keen to do so. A recent study of GPs in New South Wales reported that asthma care was still not in line with clinical practice guidelines. ${ }^{27}$ Only $13 \%$ of GPs routinely reviewed WAAPs, $27 \%$ routinely provided education about trigger factors, $30 \%$ routinely reviewed inhaler technique and $24 \%$ routinely assessed asthma severity. An improvement in strategies of implementing NAC Australia guidelines is therefore still required. A recent brief GP education programme in Sydney - the Practitioner Asthma Communication and Education programme (PACE) - has shown that an improvement in the management of paediatric asthma including having a WAAP ownership is possible. ${ }^{28}$

Given that some patients participating in this study perceived provision of a WAAP by a GP as an indicator of a 'good GP' and was mirrored by some GPs' views that providing a WAAP was an integral part of good practice, it may be helpful to use such knowledge in developing a campaign to motivate GPs to increase their rates of provision of WAAPs. As these findings are based on a relatively small number of patients and GPs participating in focus groups and interviews, it may be useful to conduct future research into whether the development and implementation of such knowledge would result in increased rates of GPs providing WAAPs.

\section{Limitations of the study}

This is a cross-sectional analysis of baseline data derived from our RCT so it is not possible to conclude a cause-and-effect relationship, especially as examination of WAAPs was only a secondary focus of the original study. Although the response rate was satisfactory, we cannot say that participants are representative of all Australian general practice patients with asthma. The patient focus groups (both pre- and post-RCT) included a small number of patients with COPD, but this was taken into account in the analysis process. Hence, our combined method approach, relatively large sample size, and the use of objective classification of control and severity have ensured fairly robust findings.

In conclusion, despite improvement in the rate of ownership of WAAPs in the population of Melbourne with

\section{Lessons Learned}

1. Information on WAAP use as well as ownership is necessary to improve insights regarding the benefit or otherwise of WAAPs.

2. We need to broaden our understanding of WAAPs and whether being symptom- or peak flow-based makes any difference to their use by people living with asthma.

3. Additional and more effective strategies are required to improve rates of GP prescription of WAAPs in Australia.

asthma, WAAP ownership is still too low and there is scope for further improvement in health outcomes. Patients who require ED presentations were far more likely to have WAAPs. This raises the question as to whether a more interactive multimedia approach - such as the evidence-based National Heart Lung and Blood Institute interactive multimedia seminar 'Physician Asthma Care Program' (http://www.nhlbi.nih.gov/health/prof/lung/asthma/ pace/index.htm) or the Sydney 'Practitioner Asthma Communication and Education Program' - to promoting asthma guidelines is needed to improve GP prescription of WAAPS across all age groups in Australia.

\section{Acknowledgements}

We wish to thank Anne Adikari, Lorien Barrie, Bernadette Flanagan, Sabrina Gupta, Joan Green and Tom Lanigan for data collection and entry. Spirometry was reported by Amanda Griffiths, Celia Lanteri, John Massie, Jennifer Perrett and Helen Whitford. The advisory board comprised Anne Bourke, Geoff Broomhall, Max de Clifford, Fiona Duffy, David Hayne, Amjad Hussain, Gary Irving, John Massie, Judi Wicking and Doris Young. We also wish to thank all participating Divisions of General Practice, general practitioners, practice staff and patients.

\section{Statement of Funding}

The trial was funded by the National Health \& Medical Research Council (NHMRC) of Australia.

\section{Conflicts of interest}

Eleonora Del Colle is the Director of Pulmetrics Pty Ltd, the company that performed the spirometry for the study.

She is one of the Principal Authors of the National Asthma Council Spirometry Course for General Practitioners, and has been presenting this course nationally over the last 18 months. The other authors have no conflicts of interest to declare.

\section{References}

1. Guevara JP, Wolf FM, Grum CM, Clark NM. Effects of educational interventions for self management of asthma in children and adolescents: systematic review and meta-analysis. BMJ 2003;326(7402):1308-09

2. National Asthma Council Australia. Asthma Management Handbook 2006: Asthma action plans. Melbourne, Australia, 2006.

3. National Institutes of Health; National Heart, Lung, and Blood Institute. Guidelines for the Diagnosis and Management of Asthma: Update on Selected Topics 2002. NIH Publication 97-4051. Washington, DC: US Dept of Health and Human Services, 2002.

4. Zemek RL, Bhogal SK, Ducharme FM. Systematic review of randomized controlled trials examining written action plans in children: what is the plan? Arch Pediatr Adolesc Med 2008;162(2):157-63. http://dx.doi.org/10.1001/ archpediatrics.2007.34

5. Powell H, Gibson PG. Options for self-management education for adults with 
asthma. Cochrane Database Syst Rev 2002;(3):CD004107.

6. Gupta RS, Weiss KB. The 2007 National Asthma Education and Prevention Program Asthma Guidelines: accelerating their implementation and facilitating their impact on children with asthma. Pediatrics 2009;(Suppl 123):S193-8. http://dx.doi.org/10.1542/peds.2008-2233J

7. Global Initiative for Asthma. Global Strategy for Asthma Management and Prevention. Bethesda, MD: National Institutes of Health; 2009 update.

8. British Thoracic Society; Scottish Intercollegiate Guidelines Network. British guideline on the management of asthma: quick reference guide. May 2008, revised 2009. http://www.brit-thoracic.org.uk/Portals/0/Clinical\% 20Information/Asthma/Guidelines/arg101\%20revised\%202009.pdf

9. Becker $A$, Lemière $C$, Bérubé $D$, et al. Asthma Guidelines Working Group of the Canadian Network For Asthma Care. Summary of recommendations from the Canadian Asthma Consensus guidelines, 2003. CMAJ 2005;173(Suppl 6):S311.

10. Gibson PG, Powell H. Written action plans for asthma: an evidence-based review of the key components. Thorax 2004;59(2):94-9. http://dx.doi.org/10.1136/thorax.2003.011858

11. Bhogal S, Zemek R, Ducharme FM. Written action plans for asthma in children. Cochrane Database Syst Rev 2006;(3):CD005306.

12. Toelle BG, Ram FS. Written individualised management plans for asthma in children and adults [update of: Cochrane Database Syst Rev 2002;(3):CD002171]. Cochrane Database Syst Rev 2004;(2):CD002171.

13. Tapp S, Lasserson TJ, Rowe BH. Education interventions for adults who attend the emergency room for acute asthma. Cochrane Database Syst Rev 2007;(3):CD003000. http://dx.doi.org/10.1002/14651858.CD003000.pub2.

14. Agrawal SK, Singh M, Mathew JL, Malhi P. Efficacy of an individualized written home-management plan in the control of moderate persistent asthma: a randomized, controlled trial. Acta Paediatr 2005;94(12):1742-6.

15. Creswell JW. Research design: qualitative, quantitative, and mixed method approaches. 2nd ed. Thousand Oaks, California: Sage Publications, 2003.

16. Abramson MJ, Schattner RL, Sulaiman ND, et al. Spirometry and regutar follow up are not associated with improved health outcomes in general practice patients with asthma or COPD: a cluster randomised controlled trail: MJA 2010;193(2):104-09.
17. Massie J, Efron D, Cerritelli B, et al. Implementation of evidence based guidelines for paediatric asthma management in a teaching hospital. Arch Dis Child 2004;89(7):660-4. http://dx.doi.org/10.1136/adc.2003.032110

18. Nathan RA, Sorkness CA, Kosinski M, et al. Development of the asthma control test: a survey for assessing asthma control. I Allergy Clin Immunol 2004;113(1):59-65. http://dx.doi.org/10.1016/j.jaci.2003.09.008

19. Minichiello V, Aroni R, Hay T. In-Depth Interviewing: Principles, Techniques and Analysis. Sydney: Pearson Education Australia, 2008.

20. Morse JM. Principles of mixed methods and multimethod research design. In: Tashakkori A, Teddlie C, eds. Handbook of Mixed Methods in Social and Behavioral Research. Thousand Oaks, California: Sage Publications, 2003: 189-208.

21. Stryker S. From Mead to a structural symbolic interactionism and beyond. Ann Rev Socio/ 2008;34:15-31. http://dx.doi.org/10.1146/annurev.soc.34.040507.134649

22. Sulaiman ND, Barton CA, Abramson MJ, et al. Factors associated with ownership and use of written asthma action plans in North-West Melbourne. Prim Care Respir J 2004;13(4):211-17. http://dx.doi.org/10.1016/j.pcrj.2004.04.002

23. Douglass J, Aroni R, Goeman D, et al. A qualitative study of action plans for asthma. BMJ 2002;324:1003.

24. Ruffin RE, Wilson D, Southcott A, Smith B, Adams RJ. A South Australian population survey of the ownership of asthma action plans. Med J Aust 1999;171(7):348-51.

25. Barton C, Abramson M, Aroni R, et al. What determines knowledge of asthma among young people and their families? J Asthma 2002;38(8):701-09. http://dx.doi.org/10.1081/JAS-120015793

26. Matheson M, Wicking J, Raven J, et al. Asthma management: how effective is it in the community? Int Med J 2002;32:451-6. http://dx.doi.org/10.1046/.14455994.2002.00273.x

27. Barton C, Proudfoot J, Amoroso C, et al. Management of asthma in Australian general practice: care is still not in line with clinical practice guidelines. Prim Care Respir J 2009; 18(2):100-05.

28. Shah S, Sawyer SM, Mellis CM, et al. Improving paediatric asthma management through provider education: a randomised controlled trial. Respirology 2010;15(Suppl 1):A29.

\section{Available online at http://www.thepcrj.org}


N Sulaiman et al.

\section{Appendix 1.}

Question (13m) asked of adult participants with asthma:

Do you have written instructions from your doctor on how to manage your asthma if it gets worse or if you have an attack?

Question (8a) asked of parents of children with asthma:

A written asthma action plan is a set of instructions which tells you what medicines your child should be taking every day and what to do if your child is having an asthma attack or his/her symptoms are getting worse.

Do you have a written asthma action plan for your child?

Please note that these questions were also used to initiate discussion about WAAPs both in the focus group sessions before and after the RCT and in the individual patient interviews (but while retaining the same intent and meaning were often more appropriately worded to fit with the conversations as they developed). 